\title{
O LEITOR RUMINANDO EM CIMA DO NADA
}

\author{
SALMA FERRAZ 1
}

FERRAZ, S. O leitor ruminando em cima do nada. Semina: Londrina, Ci. Sociais/Humanas, v. 17, n. 3, p. 313-320, set. 1996.

RESUMO: No presente artigo, analisaremos Esaú e Jacó a partir dos pressupostos teóricos da Estilística estrutural proposta por Michael Riffaterre.

\section{UNITERMOS: Literatura Brasileira; Machado de Assis; Esaú e Jacó; Estilística; Michael Riffaterre.}

"...Mas o estilo não é o homem." Machado de Assis

Embora a frase "o estilo é o próprio homem" atribuída a Buffon, tenha um sentido bem diverso daquele que se lhe atribui se recolocada no seu contexto ${ }^{2}$, vamos manter neste artigo o sentido geral comumente atribuído à frase. Mas, para Michael Riffaterre (teórico norteamericano) e para o escritor Machado de Assis o estilo é muito mais que o próprio homem. Como os nomes do teórico americano e do escritor brasileiro se relacionam é o que constataremos no decorrer deste ensaio. Por enquanto, fiquemos apenas com Michael Riffaterre, criador da estilística estrutural.

Os estudos e o modelo proposto por Jakobson, que estava mais preocupado com o processo da comunicação em geral, foram incorporados pela teoria de Riffaterre, porém modificados e ampliados, visto que o crítico estava preocupado com os problemas literários em si. À poética do modelo proposto por Jakobson, Riffaterre preferiu chamar de Função Estilística, uma vez que a designação "poética" limitava a atuação ao campo da poesia, o que não ocorre com a designação estilística.

A Função Estilística seria, portanto, a parte da lingüística que estuda a percepção da mensagem, centrada na mensagem, por isso o crítico considera que todas as outras cinco funções são intensificadas e complementadas por ela.

A análise estilística preocupa-se mais com o destinatário da mensagem que com o emissor e, ao invés de estudar todos os aspectos de uma estrutura, limita-se àqueles cuja percepção é imposta ao receptor no ato da comunicação.

A estilística proposta por Riffaterre preocupa-se com as reações do leitor perante o texto. E, nesse sentido, o teórico institui a figura do arquileitor. Arquileitor não significa nacessariamente um leitor privilegiado, mas um grupo de leitores comuns que apontariam o que thes despertou a atenção no texto lido. $O$ arquileitor teria $O$ discernimento para perceber os estímulos estilísticos presentes no texto. A importância desse fato é que os estímulos percebidos pelo arquileitor no texto "convergem para os pontos nodais do texto" (12, p. 50).

Para o crítico, o estilo não seria o resultado de uma sucessão de figuras e tropos, mas "entende-se o estilo como um reforço (emphasis) - expressivo, afetivo ou estético." (12, p. 32). Outra definição do autor diz que "um fato de estilo será uma ruptura, um "desvio" em relação a uma norma" $(12$, p. 11), norma esta que é estabelecida pelo próprio contexto. Tais definições se aproximam da retórica antiga no sentido de nomear para persuadir.

Esses desvios é que vão chamar a atenção do leitor. Estes desvios, porém, só podem ocorrer dentro de um contexto estilístico. E o que vem a ser um contexto estilístico?

"O contexto estilístico é um pattern lingüístico rompido por um elemento que é imprevisível, e o contraste que resulta desta interferência é o estímulo estilístico." (12, p. 56)

O contexto estilístico seria a norma, um padrão que é quebrado, desestruturado por um elemento imprevisível. O contraste resultante deste fato é que vai ser o estímulo estilístico para o leitor.

Portanto, um dos principais eixos da teoria proposta por Riffaterre é que o autor enquanto emissor de um determinado texto pode exercer um controle da decodificação. Uma vez que o escritor não conta com certos recursos, como por exemplo, num teatro, onde $o$

\footnotetext{
${ }^{1}$ Professora Assistente do Departamento de Língua e Literaturas Vernáculas da Universidade Federal de

Santa Catarina e Mestre em Literaturas de Língua Portuguesa pela UNESP - São Paulo - S.P.

${ }^{2}$ Conforme P. Guirand. A Estilística. São Paulo: Mestre Jou, 1970, p. 49-50.
} 
autor percebe a reação dos espectadores (reação verbal e facial) face a face, deve se utilizar de recursos lingüísticos para impor, chamar a atenção do leitor justamente para os "pontos nodais do texto." Estes realces em algumas partes do texto são necessários para que o leitor não possa "omiti-los sem mutilar o texto" e não possa "decifrá-los sem achá-los significativos" (12, p. 32).

A convergência de processos estilísticos é outra noção introduzida pelo teórico. Trata-se de um agrupamento de recursos estilísticos que demonstram a consciência do codificador no controle da decodificação por parte do leitor.

Numa primeira leitura, rápida, superficial e às vezes enganosa, o leitor se baseia na previsibilidade decodificação mínima do texto. Dessa forma o que o autor considera importante pode ser deixado de lado. Assim sendo, o que é importante deve ser igualmente imprevisível.

É através da baixa previsibilidade que se pode conseguir controlar a decodificação. Segundo o teórico, o contexto estilístico se apresenta como uma norma, padrão que sempre é rompido por um elemento imprevisível. Dentro dessa noção de previsibilidade, e imprevisibilidade observamos que:

"O que compõe a estrutura estilística de um texto é uma sequência de elementos marcados contrastando com elementos não marcados, de díades, de grupos binários cujos pólos - contexto/ contraste em relação a esse contexto - são inseparáveis, um não existindo sem o outro logo, cada fato de estilo compreende um contexto e um contraste." $(12$, p. 63/64)

Dessa forma, cada vez que um contexto (pattern)/padrão/norma for rompido por algo imprevisível, isso gerará um contraste.

Todos esses recursos (fato de estilo, convergência, clichês renovados, etc) são utilizados pelo codificador para impor à atenção do leitor elementos que julga importantes para a compreensão da obra $e$ que não poderiam passar despercebidos.

Ou seja, todos os leitores de um determinado texto terão a sua atenção despertada para certas partes distintas do texto. Todos pararão em determinadas partes da leitura e o escritor, antecipadamente, já sabe disso. E surge uma pergunta: os leitores terão a mesma interpretação desses "pontos nodais do texto"? Não importa, o essencial é que os leitores tenham a sua atenção despertada para aqueles pontos que o escritor julgou conveniente destacar.

Esta explanação geral da teoria de Riffaterre se faz necessária porque ela vai nos servir de suporte teórico para análise de Esaú e Jacó de Machado de Assis. É aqui que os nomes do teórico norte-americano e do escritor brasileiro se cruzam.
Em 1881, Machado de Assis lança Memórias Póstumas de Brás Cubas, que é considerado pelos críticos como um marco decisivo na literatura brasileira e na obra de Machado. Segundo os críticos, seria o marco da transição de Machado para o que se convencionou chamar de "fase madura". Memórias Póstumas de Brás Cubas instaura o mundo carnavalizado, o mundo às avessas, e é a marca registrada daquilo que também se convencionou chamar de "estilo machadiano". E o que caracterizaria o estilo machadiano?. Respondemos: elegância, correção, equilíbrio, clareza, narrativa problematizadora, carnavalização, humor, ironia, digressão, polifonia, paródia, leitor incluso, intertextualidade. Enfim, o livro é um verdadeiro laboratório de produção textual, uma oficina de fazer poético, ao qual Schwarz tão bem denominou de "salada intelectual".

Não poderíamos aqui comentar todos os itens do estilo machadiano, pois falta-nos tempo e espaço, mas um dos fatores explorados ao máximo por Machado nos interessa de modo especial: a recusa do leitor estático, inerte.

Machado provoca, instiga, pertuba, desafia o seu leitor, fazendo-o constantemente participar da sua criação ficcional, implícita ou explicitamente, quase como uma espécie de personagem-leitor. O escritor exige uma certa aderência do leitor ao texto para que ele possa participar da sua cosmovisão. Lembramos aqui a famosa definição de leitor ruminante com quatro estômagos no cérebro, genial e estilisticamente concebida por Machado de Assis.

O leitor machadiano deve enfrentar o seu texto como algo meio selvagem, uma verdadeira luta numa floresta de encantos e desencantos, cheia de areia movediça, na qual a única certeza é o labirinto, a dúvida. O leitor não pode se esquivar deste chamamento que se dá em todas as direções: referencial, fático, metalingüístico, apelativo. Esse chamamento visa controlar a decodificação por parte do leitor.

As inovações na arte de narrar, a consciência plena do fazer poético, a recusa do leitor passivo, o ciframento/codificação de partes importantes do texto, visando chamar a atenção do leitor e assim exercer um controle na decodificação, são características da obra machadiana que nos dão base e nos autorizam a usar a estilística estrutural para análise das mesmas.

Assim, analisaremos Esaú e Jacó nos seus direcionamentos referencial, fático, apelativo e metalingüístico, recuperando e ressaltando em todos eles a Função Estilística proposta por Riffaterre, para observarmos como se procede o controle da decodificação por parte do escritor, e como este impõe a sua cosmovisão ao leitor.

Segundo Riffaterre, há duas fases para a compreensão estilística da obra: a fase heurística e a fase hermenêutica. Na fase heurística, faz-se um levantamento das partes da obra em que apareçam 


\section{CAPÍTULO 8}

\section{Nem Casal, Nem General}

Nem casal, nem general. No dia sete de abril de 1870 veio à luz um par de varões tão iguais, que antes pareciam a sombra um do outro, se não era simplesmente a impressão do olho, que via dobrado." (02, p. 27)

O primeiro parágrafo "Cuidava trazer um general..." está inserido num contexto estilístico, num pattern, em que há o relato da gravidez de Natividade. Ela pensava estar gerando um filho homem (general) ou um casal. A estilização já se dá dentro deste contexto, pois havia, segundo o narrador, um casal que "aprendia a desamar de véspera". Esta imagem metafórica aplicada ao feto como um casal que aprendia a desamar de véspera, ou seja, antes de nascer é riquíssima. Machado fecha o parágrafo repentinamente para iniciar o Capítulo 8 e aí ocorre o imprevisível, a quebra do contexto, a ruptura do pattern pela negação dupla: "Nem Casal, Nem General". O título do Capítulo 8 encerra o capítulo anterior e inicia literal e rapidamente o próprio capítulo 8. A negação dupla "Nem casal, Nem General", acompanhado dos ecos (Casal-General) causam a imprevisibilidade que gera um estranhamento no leitor. Então temos o seguinte esquema: Contexto/Pattern (gestação e pensamentos de Narratividade) - Contraste/ Ruptura/Imprevisibilidade (Nem Casal, Nem General) separando os capítulos, nomeando o capítulo 8 e sendo repetido integralmente na primeira frase deste capítulo volta ao contexto.

No final da frase temos a menção de um olhar diferente "...se não era simplesmente a impressão que via dobrado". Este ver dobrado vai servir de base para uma série de outros procedimentos estilísticos/fatos de estilo no decorrer do texto, dos quais citamos apenas alguns: "gesto de dois sexos" (02, p. 33), "Viu então que estava sem um nem outro, sem dois nem um só fundido de ambos" (02, p. 116), "Ambos quais? perguntou Flora" $(02, p .140)$. Este ver dobrado também funciona como uma espécie de alerta ao leitor de que deve ver tudo dobrado, desconfiando de tudo.

No final do Capítulo 44, temos outro exemplo de referencialidade tratada estilisticamente.

\begin{abstract}
"Paulo ainda se declarou capaz de derrubar a monarquia com dez homens, e Pedro de extirpar o gérmem republicano com um decreto. Mas o ex-ministro, sem mais decreto que uma caçarola, nem mais homens que o seu cozinheiro, envolveu os dois regimens no mesmo salmão delicioso." (02, p. 68)
\end{abstract}

Aqui temos o seguinte processo estilístico: Contexto-Contraste-Contexto. Cumpre lembrar que "O contexto estilístico é um pattern lingüístico rompido por um elemento que é imprevisível..." (12, p. 56). O pattern, neste exemplo, nos é fornecido pela discussão dos gêmeos sobre as preferências políticas de cada um. A ruptura se dá pela introdução do substantivo "caçarola" que é comparado a um "decreto". Mas a ironia da comparação prepara uma ruptura maior ainda que é extremamente imprevisível e gera um estranhamento: "envolveu os dois regimes no mesmo salmão delicioso." A elipse do substantivo "prato" e da preposição "de" colaboram para a imagem imprevisível e estranha: um ex-ministro envolvendo num mesmo peixe dois regimes políticos totalmente opostos.

O capítulo 73 constitui-se num dos mais ricos em termos de referencialidade e processos estilísticos de todo o livro. O próprio título "Um Eldorado" já é estilizado, pois nos remete à imagem estereotipada que percorre toda a literatura posterior aos grandes descobrimentos. Trata-se de uma visão paradisíaca, edênica a ser reencontrada no novo mundo, acompanhada de riquezas materiais. Mas o Eldorado a que o autor se refere é o brasileiro, causado pela política do Encilhamento, que gerou uma falsa idéia de progresso e dinheiro fácil naquela época; por isso parecia realmente que "o dinheiro brotava do chão" ou "caía do céu" e as "carruagens brotavam do chão". Era a epopéia do Eldorado Tupiniquim às avessas. No penúltimo parágrafo deste capítulo, o autor recorre a recursos estilísticos, através da recuperação da mitologia e literatura grega: Homero, Juno, Minerva, Ílion, que só pela citação encerram em si fatos de estilo. Mas o que nos interessa é a parte final do penúltimo parágrafo e o parágrafo final. Ao descrever as carruagens paradas ali no centro comercial do Rio de Janeiro, em meio progresso, abundância, luxo e pompa, o autor nos brinda com a seguinte imagem:

"Cocheiros e lacaios, barbeados e graves, esperando tesos e compostos, davam uma bela idéia do ofício. Nenhum aguardava o patrão, deitado no interior dos carros, com as pernas de fora. A impressão que davam era de uma disciplina rígida e elegante, aprendida em alta escola e conservada pela dignidade do indivíduo. "Casos há - escrevia o nosso Aires - em que a impassibilidade do cocheiro na boléia contrasta com a agitação do dono no interior da carruagem, fazendo crer que é o patrão que, por desfastio, trepou à boléia e leva o cocheiro a passear." (02, p. 105)

A Função Estilística aqui se faz presente através da carnavalização proposta por Bakhtin. Embora a estilística estrutural proposta por Riffaterre seja criticada como sendo hermética, voltada apenas para a estrutura do texto, ela é maleável, pois comporta, como neste caso, a introdução da carnavalização dos gêneros, o que não foi prevista por Riffaterre.

No exemplo acima, a estilização ocorre pela introdução do elemento cômico: troca de papéis entre Senhores (ricos) e lacaios (pobres), inversão brusca entre alto (ricos-ascensão) e baixo (lacaios-decadência), que são justamente alguns dos elementos que caracterizam a sátira menipéia. A figura do lacaio disciplinado, barbeado, grave, teso, composto, digno vai, paradoxalmente, de encontro à imagem do patrão, desengonçado dentro da carruagem, a ponto de se

Ci. Sociais/Hum, v. 17 , n. 3, p. $313-320$ 
pensar que "o patrão que, por desfatio, trepou à boléia e leva o cocheiro a passear". Aí está uma cena carnavalizada, pois "a menipéia é plena de contrastes agudos e jogos de oxímoros: a hetera virtuosa, a autêntica liberdade do sábio e sua posição de escravo, o imperador convertido em escravo, a decadência moral e a purificação, o luxo e a miséria, o bandido nobre, etc. A menipéia gosta de jogar com passagens e mudanças bruscas, o alto e o baixo, ascenções e decadências, aproximações inesperadas do distante e separado..."(03, p. 101).

Mas no caso do leitor, não há carnavalização, inversão brusca de papéis, ele tem que ir mesmo é dentro da carruagem, sendo levado pelo narrador. Machado nos lembra aqui a lenda infantil inglesa chamada "Grey fox", na qual a raposa cinzenta convida o seu interlocutor para um passeio nas suas costas. Machado é a raposa, ardilosa, traiçoeira e o leitor o interlocutor assustado com o convite e com o passeio proposto.

Este passeio se arrasta, parece que nada acontece no livro. É a recusa do leitor açucarado do romantismo, acostumado a muitas lágrimas, grandes encontros, questões de honra; enfim, acostumado a andar nas costas de outro bicho qualquer, menos de uma raposa.

A esta altura, assustado com o ritmo e estilo da raposa, o leitor gostaria de fazer ao codificador a pergunta insinuada no título do Capítulo 93 - "Não Ata Nem Desata". A pergunta seria: "Quem és tu, que não atas, nem desatas?". O propósito do escritor neste livro não é atar, nem desatar e sim mostrar como se faz o nó, como se tece um romance. É o nó que importa, não o atar ou desatar o mesmo.

Machado recorre a metalinguagem para dialogar consigo e com o leitor sobre a construção da obra, numa espécie de auto-crítica. As digressões metalingüísticas são extremamente estilizadas e são uma das principais características do estilo e da modernidade de Machado. O recurso metalingüístico comprova nosso argumento de bordado em cima do nada.

No final do Capítulo 22 - "Agora um Salto", temos um dos trechos mais belos e explorados de Esaú e Jacó:

"Os estados de alma que daqui nasceram davam matéria a um capítulo especial, se eu não preferisse agora um salto, e ir a 1886. O salto é grande mas o tempo é um tecido invisível em que se pode bordar tudo, uma flor, um passáro, uma dama, um castelo, um túmulo. Também se pode bordar nada. Nada em cima do invisível é a mais sútil obra deste mundo, e acaso do outro." (negrito nosso)

Aqui temos uma convergência de processos estilísticos, o que mostra a consciência do codificador na elaboração da mensagem, objetivando a decodificação, a imprevisibilidade, o estranhamento do leitor

Cada processo estilístico acima enfatiza o seguinte numa cadeia de fatos de estilo. Temos um contexto/pattern que nos é fornecido pelos Capítulo 20 e 21: a condecoração feita pelo Imperador a Agostinho e Natividade, com o título de Barão e Baronesa. Portanto, "os estados de alma que daqui nasceram" estão dentro desse contexto. A introdução da função metalingüística "davam matéria a um capítulo especial, se eu não preferisse agora um salto, e ir a 1886", cria um contraste acaba se convertendo num novo pattern (de explicação do código). Deste novo contexto faz parte "o salto é grande", que é desestruturado, rompido pela metáfora "o tempo é um tecido invisível em que se pode bordar tudo".

A estilização continua num aglomerado de processos estilísticos. Há uma série de adjetivos concretos que são usados para caracterizar o substantivo abstrato "tempo". Nota-se que estes adjetivos estão colocados em forma de enumeração: pássaro, dama, castelo, túmulo. A enumeração, a princípio, apresenta-se como ascendente, mas o adjetivo "túmulo" desestrutura a gradação ascendente, desencadeia a sequência, culmina e fulmina o leitor. Pela ascendência na gradação, o leitor poderia prever tudo: céu, amor, felicidade, nunca, porém, "túmulo".

A caracterização do tempo com adjetivos concretos se choca com a volta da abstração "também se pode bordar nada". "Nada" aqui é colocado em oposição a "tudo", citado no início da enumeração. Seguindo nossa idéia de tessitura em cima do nada, este parágrafo parece configurar perfeitamente o núcleo do livro. O autor revela aqui, não o bordado pronto, mas os desenhos, os fios tênuos, brilhantes, finíssimos com que ele borda manual e magistralmente Esaú e Jacó: pássaros, sonhos, dama (Natividade e Flora); castelo: poder/monarquia/república; túmulo: Flora/ vida e bordado em cima do nada: a própria obra. No capítulo 51, "Aqui Presente", temos outro exemplo de uso da metalinguagem:

\footnotetext{
"Supõe um fio de anedotas ou uma história comprida, coisa alheia; ainda assim podia ser deles somente, porque há estados da alma em que a matéria da narração é nada, o gosto de a fazer e de a ouvir é que é tudo. Também podia ser isto". (02, p. 78) negrito nosso
}

A primeira frase "supõe um fio de anedotas ou uma história comprida, coisa alheia; ainda assim podia ser deles somente" está dentro do pattern/contexto de uma conversa segredada entre Pedro e Flora. O comentário metalingüístico "porque há estados da alma em que a matéria da narração é nada, o gosto de a fazer e de a ouvir é que é tudo" cria o contraste, a ruptura que desperta a atenção do leitor. Também temos a oposição do tudo/nada, que por si só já se constitui num fato de estilo.

Aí está a confirmação de bordado em cima do nada, pois "há estados da alma em que a matéria da narração é nada, o gosto de a fazer e de a ouvir é que é tudo". É a própria revelação da construção interna da obra.

Outro exemplo de discurso metalingüístico está contido no Capítulo 48 - "Terpsícore". 
"Não foi outra voz, semelhante à das feiticeiras do pai nem às que falavam interiormente a Natividade, acerca dos filhos. Não, seria pôr aqui muitas vozes de mistério, coisa que, além do fastio da repetição, mentiria à realidade dos fatos. A voz que falou a Flora saiu da boca do velho Aires..." (02, p. 74)

A primeira frase "não foi outra voz, semelhante à das feiticeiras do pai nem às que falavam interiormente a Natividade, acerca dos filhos" está dentro do pattern criado pelas reflexões de Flora no baile da ilha Fiscal. Este pattern é rompido pela introdução do comentário metalingüístico que se inicia como um advérbio de negação "não; seria pôr aqui muitas vozes de mistério, coisa que, além do fastio da repetição, mentiria à realidade dos fatos". A introdução deste advérbio de negação e deste comentário metalingüístico tem o propósito específico de criar no leitor um estado de confiança no narrador, pois segundo ele, tudo é verdade, não quer exagerar em nada, nem colocar muitas vozes de mistério no parágrafo, nem repetir muito, senão "mentiria à realidade dos fatos". Recorremos novamente à metáfora da raposa cinzenta tentando enganar o passageiro que, a esta altura, está grudado à pele dela.

O direcionamento fático é uma constante no estilo machadiano. Citamos Augusto Meyer: "Também no Quincas Borba e em Esaú e Jacó, com mais freqüência no segundo, há um eu que a todo instante interfere na marcha da efabulação, explicando coisas; interpelando o leitor, dando até algumas anedotas de quebra e citando sem mais propósito os seus clássicos, ou aludindo a trechos seletos da antologia universal: a bíblia, os gregos, poetas velhos e novos, algumas sobras filosóficas, o diabo..." (11, p. 331)

Meyer incorre num pequeno deslize ao dizer que tudo isso é feito "sem mais propósito", pois sabemos que há um propósito específico nas citações de Machado. Recuperemos os processos estilísticos dentro do direcionamento fático. Aqui recorremos aos clichês também estudados por Riffaterre. A renovação do clichê vai causar um estímulo proposital dentro da frase, rompendo com o contexto existente e com as expectativas do leitor pois "...o clichê apresenta uma expressividade forte e estável..." (12, p. 154) e por si só já encerra um fato de estilo completo.

No Capítulo 16 - "Paternalismo", temos:

"Qual deles era o padre, qual o sacristão, não sei nem, é preciso. A missa é que era a mesma, e o evangelho começava como o de S. João (emendado): "No princípio era o amor, e o amor se faz carne." Mas venhamos aos nossos gêmeos." (02, p. 38)

O pattern nos é dado pela situação carinhosa vivida por Santos e Natividade, que tecem comentários e sussurros a respeito das considerações feitas por Plácido sobre o futuro dos gêmeos (Capítulo 15). Esses comentários carinhosos já são estilizados, pois o autor os coloca como fazendo parte de uma missa, uma missa segredada e sagrada:
"Qual deles era o padre, qual o sacristão, não sei, nem é preciso." Este pattern (o entrosamento perfeito entre o casal/padre/sacristão) é rompido pela citação do Evangelho Segundo São João "emendado" conforme irônicamente nos informa o narrador. A surpresa, o contraste é causado pela renovação do texto bíblico. $O$ original do Evangelho de São João reza: "No princípio era o Verbo, e o Verbo se fez carne". O autor altera para "No princípio era o amor, e o amor se fez carne". O substantivo "Verbo" que no contexto dos Evangelhos tem uma conotação sagrada, de encarnação, é substituído pelo substantivo "amor", que no contexto do livro significa união carnal. Nesta renovação do texto bíblico, ocorre novamente a carnavalização, a troca do sagrado pelo profano.

O título do capítulo 36 - "A Discórdia não é Tão Feia Como se Pinta", que também é a primeira frase deste capítulo, é um clichê renovado. O pattern nos é fornecido pelo Capítulo anterior (35), no qual somos informados sobre as pretensões e pensamentos dos gêmeos em relação à Flora. A frase última do Capítulo 35 está dentro deste contexto: "Ao demais, os dois gêmeos estavam ainda no ponto de falar dela nas cartas, louvá-la, descrevê-la, dizer mil coisas doces, sem ciúme." Este pattern é quebrado, desestruturado pelo corte proporcionado pelo título do capítulo 36: "A Discórdia não é Tão Feia Como se Pinta". Esta citação é de um clichê muito conhecido e desgastado pelo uso: "o diabo não é tão feio como pinta". Este contraste vai acabar se convertendo em contexto para uma convergência de processos estilísticos que se desenvolveram no restante do parágrafo.

A retomada de textos bíblicos é uma constante na obra machadiana, especialmente neste livro. Os textos mais conhecidos da Bíblia acabam funcionando como clichês que o autor renova, e causar a imprevisibilidade que choca o leitor. No final do Capítulo 81 "Ai, Duas Almas...", por si só um fato de estilo, visto que recupera Goethe, temos:

\section{"Talvez o velho Plácido deslindasse o problema em cinco minutos. Mas para isso era preciso evocá-lo, e o discípulo Santos cuidava agora de uma liquidações últimas e lucrativas. Não só de fé vive o homem, mas também de pão e seus compostos e similares." (02, p. 113)}

O contexto nos é dado pelo narrador que nos informa sobre os pensamentos de Santos em relação às previsões de Plácido no passado. Mas Santos fazia tais reflexões enquanto lidava com somas, contas e liquidações. Esse contexto de absorção e abstração é rompido pela introdução do seguinte pensamento: "Não só de fé vive o homem, mas também de pão e seus compostos e similares." É a paródia de dois textos bíblicos extremamente conhecidos: a) "O justo viverá pela fé" e b) "Não só de pão o homem viverá", que aparecem misturados e renovados nesta citação. A renovação ocorre pela negação e inversão completa do sentido primeiro dos textos bíblicos.

Este procedimento, a ruptura do pattern pela renovação de clichês permeia abundantemente o livro. 
Citamos alguns mais expressivos: "...abençoada e formosa entre as formosas" (Capítulo 6), "...eles que abram a ferro ou língua, ou simples cotovelos, o caminho da vida e do mundo" (Capítulo 17), "Pitangueira não dá manga. Não, Flora não dava para namorados" (Capítulo 70) e assim sucessivamente. Como direcionamento fático e extremamente estilizado, não poderíamos deixar de mencionar o Capítulo 73 - "Um Eldorado", na citação irônica feita pelo autor ao recuperar Cândido, Cacambo, Basilio da Gama, Uruguai, Voltaire, Lindóia.

Também não poderíamos terminar o estudo do direcionamento fático, sem citar o Capítulo 71 - "A Comissão".

"Se tais papéis mostrassem sempre o coração da gente, Batista, cujas instruções eram, aliás, de concórdia, parecia querer levar a concórdia a ferro e fogo; mas o estilo não é o homem." (02, p. 102)

O contexto/pattern é fornecido pelas reflexões do narrador acerca da comissão recebida por Batista. Abruptamente, acontece a ruptura do pattern pela renovação do clichê. A frase de Buffon se tornou tão conhecida que se converteu num clichê. Meyer, num de seus artigos intitulado "O estilo é o homem", vai discutir todas as implicações desta conhecida frase. Mas, aqui Machado resolve renovar o clichê, introduzindo a negativa no meio da frase, o que desestrutura inteiramente o seu significado original. Machado sabia que o estilo era muito mais que o homem, como também o sabia o teórico norte-americano.

Passemos, pois, ao cotejamento do direcionamento apelativo, no qual novamente aparece a intervenção saborosa e bisbilhoteira do narrador, obrigando o leitor a farejar o texto. Aqui se percebe toda "uma utilização de um sistema de infiltrações na consciência do leitor, a atmosfera de insinuação constante e discreta" (07, p. 168).

A recusa ao leitor romântico se torna evidente no direcionamento apelativo que também é extremamente estilizado. O leitor sabe que está num labirinto instituído pelo título do livro, pelo prefácio, pelo enredo que não ata e nem desata, pela ambigüidade, pela dúvida e é, constantemente e de uma maneira explícita, advertido disso. O narrador, logo no Capítulo 5, adverte que "O melhor é ler com atenção", mas não confia no leitor e continua a puxar-lhe as orelhas. Logo após este conselho, na metade do Capítulo 6 - "Maternidade", temos:

"Fosse o que fosse, quando o cupê chegou ao meio do Catete, os dois levavam as mão presas, e a expressão do rosto era de abençoados. Não davam sequer pela gente das ruas; não davam talvez por si mesmos.

Leitor, não é muito que percebas a causa daquela expressão e desses dedos abotoados. Já lá ficou dito atrás, quando era melhor deixar que a adivinhasses; mas provavelmente não a adivinharias, não que tenhas o entendimento curto ou escuro, mas porque o homem varia do homem, e tu talvez ficasses com igual expressão, simplesmente por saber que ias dançar sábado." (02, p. 25)

O contexto nos é dado pelo diálogo entre Natividade e Santos na volta da missa rezada em favor de um parente falecido. Os dois estavam de mãos dadas, expressão facial de abençoados, dedos abotoados porque Natividade estava grávida. Mas isso - leitor não sabe visto que esta revelação só seria feita no final deste parágrafo. Portanto, o contexto (a felicidade do diálogo e da expressão dos dois) é rompido por este apelo direto ao leitor "Leitor, não é muito que percebas..." - Esse chamamento rompe o padrão estabelecido, causa um estranhamento no leitor, que se sente ofendido. A quebra se dá pelo vocativo e pela negação (Leitor/não...). O sarcasmo em relação ao leitor está explícito: "mas provavelmente não a adivinharias". O advérbio de dúvida "provavelmente" questiona a capacidade de discernimento do leitor. O narrador, após o insulto, tenta se desculpar "não que tenhas o entendimento curto ou escuro", mas esta desculpa vem tarde, o leitor a esta altura já está com o seu discernimento e os seus nervos aguçados.

A provocação continua. No Capítulo 13 - "A Epígrafe", o narrador propõe auxiliar o leitor com "um par de lunetas" para que ele "penetre o que for menos claro ou totalmente escuro". O codificador tem consciência plena da exasperação do leitor. No Capítulo 27 - "De Uma Reflexão Intempestiva", o narrador constrói um diálogo hipotético com a leitora: "O que a senhora deseja, amiga minha, é chegar já ao capítulo do amor ou dos amores, que é o seu interesse particular nos livros". Esta seria a preocupação típica da leitora formada pelo romantismo, mas o codificador se revolta com essas interrogações e inquietações banais e propõe que a mesma escreva o livro: "Se quer compor o livro, aqui tem a pena, aqui tem o papel, aqui tem um admirador; mas, se quer ler somente, deixe-se estar quieta, vá de linha em linha; dou-lhe que boceje entre dois capítulos, mas espere o resto, tenha confiança no relator destas aventuras." O codificador exige confiança no seu relato e embora chame a atenção do leitor constantemente, este tem que estar consciente de que quem escreve o livro é o autor e não ele. Cabe-lhe a tarefa de ruminar nas costas da raposa.

No final do Capítulo 55 - "A mulher é a desolação do Homem", temos:

"Tal foi a conclusão de Aires, segundo se lê no Memorial. Tal será a do leitor, se gosta de concluir. Note que lhe poupei o trabalho de Aires; não o obriguei a achar por si o que, de outras vezes, é obrigado a fazer. O leitor atento, verdadeiramente ruminante, tem quatro estômagos no cérebro, e por eles faz passar e repassar os atos e os fatos, até que deduz a verdade, que estava ou parecia estar escondida." (02, p. 84) negrito nosso 
O pattern nos é dado pelo comentário do narrador/Aires (extremamente ambíguo) sobre a influência de D. Cláudia sobre o marido Batista. A frase "tal será a do leitor, se gosta de concluir" contrasta com o contexto, é imprevisível, gera um estranhamento. A ironia do narrador em relação ao leitor é ferina: "Note que Ihe poupei o trabalho de Aires; não o obriguei a achar por si o que, de outras vezes, é obrigado a fazer." Em seguida, Machado nos dá a perfeita definição do que ele espera do leitor. O emprego do verbo ruminar para caracterizar o leitor machadiano aumenta o estranhamento do leitor que se vê comparado a um animal. É a oportunidade do leitor descer das costas da raposa!

O que observamos é que o contraste fornecido pela frase "tal será a do leitor..." acaba se transformando em contexto para uma convergência de processos estilísticos, que tem o seu clímax na belissíma definição de leitor ruminante. A partir dessa denominação, o leitor ruminante tem que assumir a sua luta selvagem contra a velha raposa. Mas a floresta e a raposa continuam ardilosas: "Concluís que Flora era namoradeira e concluis mal. Leitora, é melhor negar já isto que esperar pelo tempo." (02. p. 101)

Ao chegar ao final da travessia da floresta encantada que é Esaú e Jacó, agarrado às costas da raposa, o leitor verá que valeu a pena se submeter aos caprichos e requintes do codificador.

Sobre Esaú e Jacó há muito ainda por se dizer, mas para nós nesta obra Machado quis mostrar a perfeição do seu bordado, a tessitura da obra. O livro foi bordado manualmente, artesanalmente. Um bordado tão perfeito que suplanta os próprios personagens e o próprio enredo, pois o importante para o escritor, neste livro era o bordado. Tal como Penélope, tecer e destecer, bordar e desbordar, expor o bordado em si. Como Sherazade, esta teia, este bordado era o seu viver. Não é por mera coincidência que este foi um dos seus últimos livros.

Para Machado o estilo não era o homem, o estilo superava o homem, as suas limitações, pois através dele era possível o impossível: bordar em cima do nada e fazer o leitor ruminar em cima deste nada e "nada em cima do invisível é a mais sutil obra deste mundo, e acaso do outro"(02, p. 44).

FERRAZ, S. The reader ruminanting on nothing. Semina: Ci. Sociais/Humanas, v. 17, n. 3, p. 313-320, Sep. 1996.

ABSTRACT: The present article has a central purpose, presupposed from theorical stylistic proposed by the american Michael Rifaterre, analyze the message perpection by the reader, the reaction by the part of the reader in presence of the book Esaú and Jacó by Machado de Assis. It intends to bring in connection and to investigate everything as it is called "facts of styles", the ruptures, the mistakes" that the author uses to have the total control of "decodification" and in what manner this will affect the reader to understand the act. Even though the article tries to show and localizate in the act the stylistic context, the linguistic patter, and the gathering of the stylistic processes, the low prevision, the clichés, the oposicions constrastes-contexts and carnival's influence into Literature (by Bakhtin).

KEY-WORDS: Brazilian Literature, Machado de Assis, Esaú and Jacó, stylistic structural, Michael Rifaterre, the reader's ruminanting on nothing.

\section{REFERÊNCIAS BIBLIOGRÁFICAS}

ANDRADE, Mario de. Aspectos da Litertura Brasileira. 6a. Edição, São Paulo: Martins Editora, 1978.

ASSIS, Machado de. Esaú e Jacó. 2a. Edição, Rio de Janeiro: Edições Ediouro, s/d

BAKHTIN, Mikhail. Problemas da Poética de Dostoiévski. Tradução Paulo Bezerra, Rio de Janeiro: Forense Universitária, 1981

BOSI, Alfredo. História Concisa da Literatura Brasileira. 3a. Edição, Sao Paulo: Cultrix, s/d.

CANDIDO, Antonio. Vários Escritos. 2a. Edição, São Paulo: Duas Cidades, 1977

CASTELO, José Aderaldo. Realidade e llusão em Machado de Assis. São Paulo: Companhia Editora Nacional, s/d.

COUTINHO, Afrânio. A Literatura no Brasil. Volume IV, 3a Edição revista e atualizada, Rio de Janeiro: José Olympio, 1986.
GLEDSON, John. Machado de Assis - Ficcão e História. Rio de Janeiro: Paz e Terra, 1986.

JAKOBSON, Romam. Linguística e Comunicação. 4a. Edição São Paulo: Editora Cultrix, 1970.

MERQUIOR, José Guilherme. De Anchieta a Euclides - Breve História da Literatura Brasileira. 2a. Edição, Rio de Janeiro: José Olympio, 1979

MEYER, Augusto. Textos Críticos. Organização João Alexandre Barbosa, São Paulo: Perspectiva, 1986.

RIFFATERRE, Michael. Estilistica Estrutural. Tradução de Anne Arnichand e Álvaro Lorencini, São Paulo: Cultrix, 1971

SCHWARZ, Roberto. Um Mestre na Periferia do Capitalismo/ Machado de Assis. São Paulo: Duas Cidades, 1990.

TEIXEIRA, Ivan. Apresentação de Machado de Assis. 2a. Edição, São Paulo: Martins Fontes, 1987.

Semina Ci. Sociais/Hum. v. 17, n. 3 , p. $313-320$ 